\title{
Sistem Pendukung Keputusan untuk Evaluasi Tingkat Kesejahteraan Masyarakat Menggunakan Metode PROMETHEE
}

\author{
Masna Wati ${ }^{1}$, R.H. Kimebmen Simbolon ${ }^{2}$, Joan Angelina Widians ${ }^{3}$, Novianti Puspitasari ${ }^{4}$ \\ ${ }^{1,2,3,4}$ Program Studi Informatika, Fakultas Teknik, Universitas Mulawarman \\ Jl. Sambaliung, Kampus Unmul Gn. Kelua, Kota Samarinda, Kalimantan Timur 75242 \\ e-mail: ${ }^{1}$ masnawati@fkti.unmul.ac.id, ${ }^{2}$ simbolonkimebmen@gmail.com, \\ ${ }^{3}$ angel.unmul@gmail.com, ${ }^{4}$ novia.ftik.unmul@gmail.com
}

\begin{abstract}
Abstrak
Salah satu faktor tercapainya kesejahteraan masyarakat yaitu rendahnya tingkat penduduk miskin. Pemerintah berperan penting dalam mensejahterakan masyarakat dan pengentasan kemiskinan. Seleksi tingkat kesejahteraan masyarakat adalah salah satu masalah yang memerlukan keputusan yang tepat agar bantuan disalurkan kepada masyarakat yang membutuhkan tepat sesuai target. Oleh karena itu, dibangun sistem decision support menggunakan metode Promethee. Data penelitian berupa 220 data sampel keluarga dan melibatkan 15 kriteria dalam mengevaluasi tingkat kesejahteraan masyarakat bersumber pada Survei Sosial Ekonomi Nasional oleh Badan Pusat Statistik Provinsi Kalimantan Timur. Sistem yang telah dibangun memberikan output berupa urutan prioritas kesejahteraan masyarakat yang dapat dijadikan pertimbangan bagi pemerintah atau pihak terkait dalam penyaluran bantuan agar tepat sasaran.
\end{abstract}

Kata kunci: kesejahteraan masyarakat, sistem pendukung keputusan, promethee

Abstract

One of the factors in achieving community welfare is the low poverty level. The government has an essential duty in the welfare of society and alleviating poverty. The evaluation of the welfare level is one of the problems that require the right decision so that the social assistance provided to people in need can be right on target. The study aims to deploy a system that utilizes the Promethee method for decision-makers. There is 220 family as the sample data evaluated involves 15 criteria for assessing the community welfare level sourced from the National Socio-Economic Survey by the Statistics of East Kalimantan Province. The decision support system built was able to result in priority order of community welfare level so that it could be a consideration or reference to the government or related agencies in distributing aid to make it right on target.

Keywords: public welfare, decision support system, promethee

\section{Pendahuluan}

Salah satu target utama setiap bangsa di dunia ini adalah tercapainya kesejahteraan masyarakat secara merata di penjuru negara. Salah satu faktor tercapainya kesejahteraan masyarakat yaitu rendahnya tingkat penduduk miskin [1]-[3]. Bersumber pada data Badan Pusat Statistik (BPS) pada tahun 2018, penduduk miskin di Kota Samarinda cenderung bertambah pada periode tahun 2013-2017. Angka kemisikinan di Kota Samarinda terus meningkat setiap tahun pada periode ini dan mencapai $4,77 \%$ pada tahun 2017 [3]-[5].

Pemerintah memiliki peran penting dalam mensejahterakan masyarakat, terutama dalam hal kemiskinan. Pemerintah dan masyarakat pastinya telah berusaha keras melakukan berbagai upaya yang bertujuan untuk menekan angka kemisikinan. Pemerintah baik pusat maupun daerah, dunia usaha baik sektor swata serta masyarakat ialah pihak yang seharusnya bertanggungjawab bersama dalam penanggulangan kemiskinan [6], [7]. Salah satu upaya 
penanggulangan kemiskinan dilakukan melalui pelbagai program bantuan sosial mulai dari Program Keluarga Harapan, Santunan Warga Tidak Mampu, Beras sejahtera, Bantuan Usaha, Bantuan pendidikan dan beragam lainnya [8]-[10]. Oleh karena itu, pemerintah perlu mengidentifikasi masyarakat berdasarkan tingkat kesejahteraannya agar bantuan yang disebar pada masyarakat sesuai dengan kondisi tingkat kesejahteraan masyarakat sehingga diharapkan dapat menekan angka tingkat kemiskinan [1].

Sehubungan dengan hal tersebut, maka diperlukan evaluasi kesejahteraan masyarakat melalui interpretasi urutan tingkat kesejahteraan tiap keluarga dalam menentukan prioritas keluarga yang membutuhkan bantuan. Pada penelitian [11] tentang Sistem Pendukung Keputusan (SPK) penetapan penerima Kartu Indonesia Sehat (KIS) dimana dalam proses seleksi penerima KIS digunakan metode Promethee sehingga metode ini menghasilkan rekomendasi keputusan berdasarkan urutan prioritas calon penerima. Selain itu, pada penelitian [12] tentang implementasi metode PROMETHEE dalam menentukan calon penerima bantuan PKH dimana proses pemilihan penerima bantuan menggunakan kriteria keputusan tertentu. Berdasarkan kedua penelitian ini maka metode PROMETHEE pun dapat diterapkan untuk mengevaluasi tingkat kesejahteraan masyarakat.

Penelitian ini memanfaatkan salah satu metode Multi Criteria Decison Making (MCDM) dalam mengevaluasi prioritas kesejahteraan keluarga. Metode ini memproses data dengan cara membandingkan setiap alternatif menggunakan kriteria keputusan yang telah ditetapkan. Metode MCDM yang diaplikasikan yaitu Perference Rangking Organization Method for Enrichment Evaluation (PROMETHEE). Berdasarkan hal tersebut, tujuan penelitian ini yaitu menghasilkan sebuah SPK menentukan urutan tingkat kesejahteraan masyarakat di Kota Samarinda menggunakan metode PROMETHEE. Tujuan dibangunnya perangkat lunak ini untuk memberikan output berupa prioritas tingkat kesejahteraan masyarakat yang dapat mempermudah pemerintah dalam mengevaluasi tingkat kesejahteraan masyarakat.

\section{Metode Penelitian}

\subsection{Kerangka Penelitian}

Penelitian dilaksanakan mengikuti kerangka pemikiran yang dibuat sesuai dengan kebutuhan penelitian, dimana terdiri dari beberapa tahapan kegiatan. Tahapan kegiatan penelitian ini dipresentasikan dalam Gambar 1.

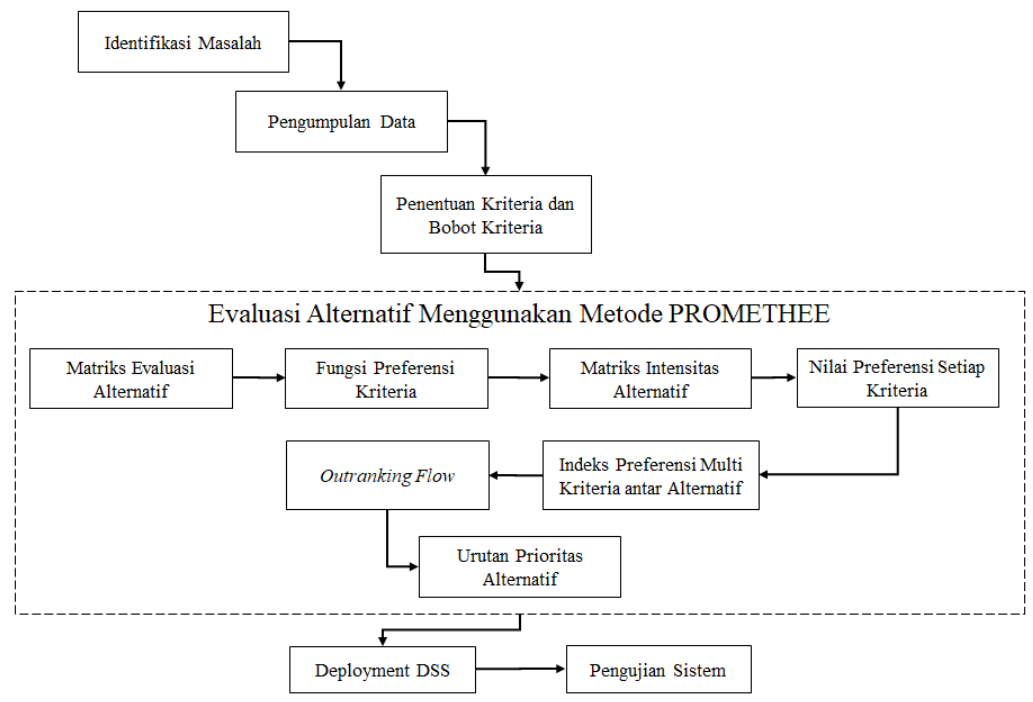

Gambar 1. Kerangka Tahapan Penelitian

Pengumpulan data dilakukan di Badan Pusat Statistik Kalimantan Timur, dimana data yang digunakan merupakan data hasil Survei Sosial Ekonomi Nasional (SUSENAS) kota Samarinda. Pada tahap ini dilakukan seleksi kriteria keputusan dari indikator-indikator SUSENAS, yaitu blok yang terkait dengan kondisi ekonomi dan sosial dasar pada setiap 
keluarga. Selain itu, pada tahap ini juga digali bobot setiap kriteria yang telah diseleksi berdasarkan besarnya keterlibatan kriteria tersebut dalam menentukan suatu keluarga menjadi kelompok masyarakat sejahtera atau tidak sejahtera.

Tahap selanjutnya, berdasarkan data yang telah diseleksi maka dilakukan pembentukan matriks evaluasi alternatif yang merupakan dataset keluarga beserta kondisi kriteria masingmasing keluarga. Dataset ini yang kemudian akan dievaluasi menggunakan metode PROMETHEE sehingga menghasilkan urutan kondisi masyarakat dari keluarga tidak sejahtera hingga keluar sejahtera.

Selanjutnya dilakukan pengembangan perangkat lunak yaitu membangun sebuah sistem pendukung keputusan dimana output sistem berupa urutan (ranking) alternatif keputusan yaitu urutan prioritas kesejahteraan masyarakat mulai dari masyarakat tidak sejahtera hingga masyarakat sejahtera. Pada fase pengembangan sistem ini juga dilakukakn pengujian sistem baik terkait keberhasilan penerapan metode PROMETHEE dalam mengevaluasi alternatif keputusan maupun fungsionalitas dari sistem tersebut.

\subsection{Kriteria evaluasi tingkat kesejahteraan masyarakat}

Data alternatif yang digunakan dalam penelitian ini sebanyak 220 keluarga di Kota Samarinda bersumber pada hasil SUSENAS BPS Provinsi Kalimantan Timur. Indikator dalam SUSENAS yang menggambarkan kondisi sosial ekonomi masyarakat digunakan sebagai kriteria dalam mengevaluasi tingkat kesejahteraan masyarakat.

Berdasarkan [13], [14] mengenai profil kemiskinan, meskipun dalam hal jumlah kemiskinan di daerah pedesaan menurun, persentase orang miskin meningkat. Upaya dan strategi telah dilaksanakan pemerintah untuk pengentasan kemiskinan seperti memberikan bantuan kepada warga miskin dalam suatu program, beberapa program dijelaskan dalam [15], [16]. Serangkaian program tersebut memiliki tujuan yang sama yaitu pengurangan kemiskinan. Peran data kemiskinan merupakan faktor penting dalam kesuksesan penyelenggaraan program [17]. Berikut indikator kemiskinan menurut BPS yang diaplikasikan pada penelitian ini, yaitu [18]-[20]:

a. Pengeluaran Per Kapita setiap bulan

b. Pekerjaan kepala RT

c. Status tempat tinggal

d. Luas lantai rumah

e. Bahan lantai rumah

f. Bahan atap rumah

g. Bahan dinding rumah

h. Fasilitas MCK

i. Sumber air utama

j. Sumber listrik

k. Bahan bakar memasak

1. Kepemilikan harta mobil

m. Asuransi kesehatan

n. Riwayat rawat inap 1 tahun terakhir

o. Ketersediaan makan yang sehat dan bergizi.

\subsection{PROMETHEE}

MCDM merupakan cabang ilmu yang bertujuan sebagai solusi dalam pengambilan keputusan pada permasalahan kompleks. MCDM dapat menyelesaikan persoalan pemilihan keputusan dari sekumpulan alternatif keputusan yang melibatkan beberapa kriteria keputusan yang kontraris [21]-[23].

PROMETHEE diperkenalkan oleh J.P. Brans [24]. PROMETHEE merupakan metode yang terdapat dalam analisis multikriteria atau MCDM yang bertujuan menetapkan urutan atau prioritas keputusan. PROMETHEE adalah metode outrangking yang memiliki cara kerja sederhana dan fleksibel dalam menganalisis masalah multikriteria.

Prinsip kerja metode ini dalam menetapkan urutan tingkat kesejahteraan keluarga mengikuti pertimbangan kaidah dasar berikut [24], [25] : 
$\operatorname{Max}\left\{\mathrm{f}_{1}(\mathrm{x}), \mathrm{f}_{2}(\mathrm{x}), \mathrm{f}_{3}(\mathrm{x}), \ldots . . \mathrm{f}_{\mathrm{i}}(\mathrm{x}), \ldots \ldots, \mathrm{f}_{\mathrm{k}}(\mathrm{x}) \mathrm{I}_{\mathrm{x}}\right.$, dimana $k$ merupakan sejumlah kumpulan keluarga yang dievaluasi dan $\mathrm{f}_{1}(i=1,2, \ldots, k)$ mewakili nilai relatif kriteria keputusan yaitu indikator evaluasi tingkat kesejahteraan masyarakat pada setiap alternatif.

Pada metode PROMETHEE, fungsi preferensi terkadang mempunyai nilai fungsi yang berbeda antar evaluasi alternatif sehingga:

$$
P(a, b)=P(f(a)-f(b))
$$

Suatu objek memiliki nilai kriteria yang lebih baik didasarkan pada nilai $f$, selanjutnya keseluruhan nilai ini untuk setiap kriteria dijadikan sebagai bobot prioritas tiap-tiap objek yang sedang dievaluasi.

Metode PROMETHEE memiliki enam bentuk fungsi preferensi kriteria. Tipe fungsi preferensi digunakan untuk menggambarkan area yang tidak sama meliputi [1], [24], [26], [27]:

1. Tipe Konvensional (Usual Criterion)

keterangan:

$$
H(d)=\left\{\begin{array}{l}
0 \text { Jika } d=0 \\
1 \text { Jika } d \neq 0
\end{array}\right.
$$

$H(d)$ = fungsi jarak kriteria antar alternatif

$d=$ nilai jarak kriteria $\{d=f(a)-f(b)\}$,

Pada kondisi $f(a)=f(b)$ maka $a$ dan $b$ sama penting (tak memiliki selisih). Jika nilai kriteria tiap alternatif berbeda, alternatif dengan nilai dominan didefinisikan sebagai preferensi mutlak.

2. Tipe Kuasi (Quasi Criterion)

keterangan:

$$
H(d)=\left\{\begin{array}{c}
0 \text { jika }-s \leq d \leq s \\
1 \text { jikad }<- \text { s ataud }>s
\end{array}\right.
$$

$H(d)=$ fungsi jarak kriteria antar alternatif

$d=$ jarak nilai kriteria $\{d=f(a)-f(b)\}$

$s=$ konstanta tetap

Jika jarak kriteria antar alternatif tidak melebihi nilai $s$ maka dua alternatif tersebut memiliki preferensi yang sama penting. Sebaliknya, jika nilai tersebut melewati nilai $s$ maka membentuk preferensi mutlak. Inisialisasi nilai $s$ diperlukan ketika kriteria kuasi digunakan. Konstanta $s$ mewakili nilai signifikansi pengaruh dari suatu kriteria.

3. Tipe Linier (Linear Criterion atau $V$-Shape)

$$
H(d)=\left\{\begin{array}{c}
\frac{d}{r}, j i k a-r \leq d \leq r \\
1, j i k a d<-r \text { atau } d>r
\end{array}\right.
$$

keterangan:

$H(d)=$ fungsi jarak kriteria antar alternatif

$\mathrm{d}=$ jarak nilai kriteria $\{d=f(a)-f(b)\}$

$r=$ nilai tren atas

Nilai preferensi meningkat secara linier terhadap nilai $d$ selama nilai $d$ berada pada rentang $-r \leq d \leq r$. Sebaliknya, ketika nilai $d$ berada diluar rentang tersebut, maka terjadi preferensi mutlak. Jika decision maker mendefinisikan kriteria menggunakan tipe ini, perlu ada inisialisasi nilai dari tren atas (nilai $p$ ).

\section{Tipe Tingkatan (Level Criterion)}




$$
\text { (d) }=\left\{\begin{array}{c}
0, \text { jika } d \leq s \\
0,5 \text { jika } s<d \leq r \\
1 \text { jika } d>r
\end{array}\right.
$$

keterangan:

$H(d)=$ fungsi jarak kriteria antar alternatif

$\mathrm{d}=$ nilai jarak kriteria $\{d=f(a)-f(b)\}$

$p=$ nilai tren atas

$q=$ konstanta tetap

Pada kondisi ini, konstanta $s$ dan tren atas $\mathrm{r}$ diberikan secara simultan. Ketika $d$ berada diantara $s$ dan $r$ maka terjadi preferensi lemah $(H(d)=0.5)$.

5. Tipe Linear dengan area tak berbeda (Linear Criterion with Indifference)

keterangan:

$$
H(d)=\left\{\begin{array}{c}
0 \text { jika } d \leq s \\
\frac{d-s}{p-s}-s, j i k a ~ s<d \leq r \\
1 \text { jika } d>r
\end{array}\right.
$$

$H(d)=$ fungsi jarak kriteria antar alternatif

$\mathrm{d}=$ nilai jarak kriteria $\{d=f(a)-f(b)\}$

$r=$ nilai tren atas

$s=$ konstanta tetap

Pada saat di area antara dua tren $q$ dan $p$, decision maker mempertimbangkan bahwa peningkatan nilai preferensi terjadi secara linier hingga mencapai preferensi mutlak saat $d$ lebih besar daripada $r$.

6. Tipe Gaussian

$$
H(d)=1-e\left\{\frac{d^{2}}{2 \sigma^{2}}\right\}
$$

keterangan:

$H(d)=$ fungsi jarak kriteria antar alternatif

$\mathrm{d}=$ jarak nilai kriteria $\{d=f(a)-f(b)\}$

Indeks preferensi multikriteria merupakan rata-rata fungsi preferensi $\mathrm{P}_{\mathrm{i}}$.

$$
\varphi(a, b)=\sum_{i=1}^{n} \pi P_{i}(a, b): \forall a, b \in A
$$

Outrangking Negatif (entering flow):

$$
\phi^{-}(a)=\frac{1}{n-1} \sum \varphi(a, x) x \in A
$$

Outrangking Positif (leaving flow):

$$
\phi^{+}(a)=\frac{1}{n-1} \sum \varphi(x, a), x \in A
$$

Net flow:

$$
\phi(a)=\phi^{+}(a)-\phi^{-}(a)
$$

\section{Hasil dan Pembahasan}

Berdasarkan 220 alternatif pada data set, terdapat 199 keluarga dikategorikan sebagai keluarga sejahtera dan 21 keluarga sebagai keluarga tidak sejahtera. Bobot tiap kriteria (indikator) mewakili besarnya tingkat kepentingan indikator pada proses pengambilan keputusan diberikan pada Tabel 1. 
Tabel 1. Indikator evaluasi tingkat kesejahteraan masyarakat

\begin{tabular}{|c|c|c|c|}
\hline Indikator & $\begin{array}{c}\text { Bobot } \\
\text { Kriteria }\end{array}$ & Parameter & Nilai \\
\hline \multirow[t]{3}{*}{ Pengeluaran Per Kapita/Bulan (I1) } & 0.077 & Rendah & 0,310 \\
\hline & & Normal & 0,226 \\
\hline & & Tinggi & 0,070 \\
\hline \multirow[t]{5}{*}{ Pekerjaan KRT (I2) } & 0,062 & Usaha tanpa buruh & 0,451 \\
\hline & & Usaha dengan buruh tidak tetap & 0,764 \\
\hline & & Usaha dengan buruh tetap & 0,469 \\
\hline & & Buruh/Karyawan/Pegawai & 0,303 \\
\hline & & Pekerja tidak tetap & 0,991 \\
\hline \multirow[t]{6}{*}{ Jenis Asuransi (I3) } & 0,050 & Tidak ada & 0 \\
\hline & & BPJS PBI & 0,323 \\
\hline & & BPJS NON PBI & 0,051 \\
\hline & & Jamkesda & 0 \\
\hline & & Asuransi Swasta & 0 \\
\hline & & Asuransi Perusahaan/Kantor & 0 \\
\hline \multirow{2}{*}{$\begin{array}{l}\text { Riwayat Rawat Inap } 1 \text { tahun } \\
\text { terakhir (I4) }\end{array}$} & 0,053 & $\mathrm{Ya}$ & 0 \\
\hline & & Tidak & 0,467 \\
\hline \multirow{2}{*}{$\begin{array}{l}\text { Ketersediaan Makan yang Sehat } \\
\text { dan Bergizi (I5) }\end{array}$} & 0,048 & $\mathrm{Ya}$ & 0,722 \\
\hline & & Tidak & 0,335 \\
\hline \multirow[t]{4}{*}{ Status Tempat Tinggal (I6) } & 0,045 & Hak milik penuh & 0,365 \\
\hline & & Kontrak/Sewa & 0,845 \\
\hline & & Bebas Sewa & 0,529 \\
\hline & & Rumah Dinas & 0 \\
\hline \multirow[t]{3}{*}{ Luas Lantai Rumah (I7) } & 0,063 & $>100 \mathrm{~m}^{2}$ Luas & 0,199 \\
\hline & & $>=50 \mathrm{~m}^{2}$ Cukup & 0,374 \\
\hline & & $<50 \mathrm{~m}^{2}$ Sempit & 0,983 \\
\hline \multirow[t]{5}{*}{ Bahan Atap Rumah (I8) } & 0,047 & Beton & 0 \\
\hline & & Genteng & 0,179 \\
\hline & & Asbes & 0 \\
\hline & & Seng & 0,495 \\
\hline & & Kayu/Sirap & 0,985 \\
\hline \multirow[t]{2}{*}{ Bahan Dinding Rumah (I9) } & 0,092 & Tembok & 0 \\
\hline & & Kayu/Papan & 0,861 \\
\hline \multirow[t]{4}{*}{ Bahan Lantai Rumah (I10) } & 0,092 & Keramik & 0 \\
\hline & & Ubin/Tegel & 0 \\
\hline & & Kayu/Papan & 0,837 \\
\hline & & Semen/Bata Merah & 0,773 \\
\hline \multirow[t]{3}{*}{ Sumber Air Utama (I11) } & 0,055 & Ledeng & 0,391 \\
\hline & & Sumur Bor & 0,592 \\
\hline & & Air Permukaan & 0,946 \\
\hline \multirow[t]{2}{*}{ Fasilitas MCK (I12) } & 0,024 & Umum & 1 \\
\hline & & Pribadi & 0,442 \\
\hline \multirow[t]{3}{*}{ Sumber Listrik PLN (I13) } & 0,083 & Non Listrik/Listrik <900 W & 0,592 \\
\hline & & Listrik $900 \mathrm{~W}$ & 0,485 \\
\hline & & Listrik $=>1300 \mathrm{~W}$ & 0,196 \\
\hline \multirow[t]{5}{*}{ Bahan Bakar Utama (I14) } & 0,103 & Kayu Bakar & 0 \\
\hline & & Minyak Tanah & 0 \\
\hline & & Elpiji $3 \mathrm{KG}$ & 0,555 \\
\hline & & Elpiji 5,5 KG & 0 \\
\hline & & Elpiji $12 \mathrm{KG}$ & 0 \\
\hline
\end{tabular}




\begin{tabular}{cclc}
\hline \multirow{2}{*}{ Indikator } & Bobot & \multicolumn{1}{c}{ Parameter } & Nilai \\
& Kriteria & & \\
\cline { 3 - 4 } & & Listrik & 0 \\
Kepemilikan Mobil (I15) & 0,107 & Tidak Punya & Punya \\
& & & 0,594 \\
& &
\end{tabular}

Selanjutnya, alternatif dievaluasi menggunakan metode Promethee sehingga diperoleh urutan prioritas alternatif yang menggambarkan tingkat kesejahteraan masyarakat. Langkah metode PROMETHEE dalam menetapkan tingkat kesejahteraan keluarga diuraikan dibawah ini: 1) Membentuk matriks evaluasi yaitu rating padanan setiap alternatif keputusan dengan kriteria yang dilibatkan, dinyatakan dalam Tabel 2.

Tabel 2. Matriks evaluasi alternatif

\begin{tabular}{cccccc}
\hline Alternatif & I1 & I2 & I3 & $\ldots$ & I15 \\
\hline W1 & 0,07 & 0,451 & 0,051 & $\ldots$ & 0,594 \\
W2 & 0,07 & 0,451 & 0,051 & $\ldots$ & 0,594 \\
W3 & 0,07 & 0,451 & 0,051 & $\ldots$ & 0,594 \\
W4 & 0,07 & 0,469 & 0,051 & $\ldots$ & 0,096 \\
W5 & 0,07 & 0,451 & 0,051 & $\ldots$ & 0,096 \\
$\vdots$ & $\vdots$ & $\vdots$ & $\vdots$ & $\ddots$ & $\vdots$ \\
W220 & 0,226 & 0,303 & 0,051 & $\ldots$ & 0,096 \\
\hline
\end{tabular}

2) Menetapkan fungsi preferensi kriteria. Tipe fungsi kriteria yang digunakan dalam menentukan prioritas tingkat kesejahteraan masyarakat disajikan dalam Tabel 3.

Tabel 3. Fungsi preferensi kriteria

\begin{tabular}{clcc}
\hline \multirow{2}{*}{ Kriteria } & \multirow{2}{*}{ Preferensi } & \multicolumn{2}{c}{ Parameter } \\
& & $\mathrm{p}$ & $\mathrm{q}$ \\
\hline I1 & Linier (3) & 0,000382 & 0,083618 \\
I2 & Quasi (2) & 0,002455 & 0,537545 \\
I3 & Level (4) & 0,001236 & 0,270764 \\
I4 & Usual (1) & 0 & 0 \\
I5 & Usual (1) & 0 & 0 \\
I6 & Level (4) & 0,002182 & 0,477818 \\
I7 & Linier quasi (5) & 0,002768 & 0,606232 \\
I8 & Quasi (2) & 0,003664 & 0,802336 \\
I9 & Usual (1) & 0 & 0 \\
I10 & Quasi (2) & 0,000291 & 0,063709 \\
I11 & Quasi (2) & 0,001609 & 0,352391 \\
I12 & Usual (1) & 0 & 0 \\
I13 & Level (4) & 0,000486 & 0,106514 \\
I14 & Usual (1) & 0 & 0 \\
I15 & Usual (1) & 0 & 0 \\
\hline
\end{tabular}

3) Menentukan intensitas alternatif berdasarkan dominasi kriteria antar alternatif $(d)$ untuk masing-masing kriteria menggunakan persamaan (1).

Untuk kriteria I1:

$$
=0.07-0.07=0 \quad P(1,2)=P(f(K 1)-f(K 2))
$$

sehingga nilai $d$ untuk masing-masing kriteria ditampilkan dalam Tabel 4. 
Tabel 4. Matriks intensitas alternatif

\begin{tabular}{cccccc}
\hline Alternatif & I1 & I2 & I3 & $\ldots$ & I15 \\
\hline $\mathrm{W}(1,2)$ & 0 & 0 & 0 & $\ldots$ & 0 \\
$\mathrm{~W}(1,3)$ & 0 & 0 & 0 & $\ldots$ & 0 \\
$\mathrm{~W}(1,4)$ & 0 & $-0,018$ & 0 & $\ldots$ & 0,498 \\
$\mathrm{~W}(1,5)$ & 0 & 0 & 0 & $\ldots$ & 0,498 \\
$\vdots$ & $\vdots$ & $\vdots$ & $\vdots$ & $\ddots$ & $\vdots$ \\
$\mathrm{W}(1,220)$ & $-0,156$ & 0,148 & 0 & $\ldots$ & 0,498 \\
\hline
\end{tabular}

4) Elemen-elemen dari matriks intensitas alternatif disubtitusi menggunakan nilai indeks preferensi masing-masing kriteria menggunakan tipe fungsi preferensi kriteria pada Tabel 3 menggunakan persamaan (1)-(6) sehingga diperoleh nilai preferensi $(H(d))$ tiap kriteria yang dimiliki oleh alternatif. Hasilnya ditampilkan pada Tabel 5.

Tabel 5. Nilai preferensi setiap kriteria

\begin{tabular}{cccccc}
\hline Alternatif & I1 & I2 & I3 & $\ldots$ & I15 \\
\hline $\mathrm{W}(1,2)$ & 0 & 0 & 0 & $\ldots$ & 0 \\
$\mathrm{~W}(1,3)$ & 0 & 0 & 0 & $\ldots$ & 0 \\
$\mathrm{~W}(1,4)$ & 0 & 0 & 0 & $\ldots$ & 1 \\
$\mathrm{~W}(1,5)$ & 0 & 0 & 0 & $\ldots$ & 1 \\
$\vdots$ & $\vdots$ & $\vdots$ & $\vdots$ & $\ddots$ & $\vdots$ \\
$\mathrm{W}(1,220)$ & 0 & 1 & 0 & $\ldots$ & 1 \\
\hline
\end{tabular}

5) Menentukan indeks preferensi multi kriteria antar alternatif, $\varphi(a, b)$, menggunakan persamaan (8) yaitu total penjumlahan $(H(d))$ yang telah dikalikan dengan masing-masing bobot kriteria sehingga diperoleh hasil pada Tabel 6.

Tabel 6. Indeks preferensi multi kriteria antar alternatif

\begin{tabular}{cccccc}
\hline Alternatif & I1 & I2 & $\ldots$ & I15 & $\varphi(a, b)$ \\
\hline $\mathrm{W}(1,2)$ & 0 & 0 & $\ldots$ & 0 & 0,2813 \\
$\mathrm{~W}(1,3)$ & 0 & 0 & $\ldots$ & 0 & 0,0749 \\
$\mathrm{~W}(1,4)$ & 0 & 0 & $\ldots$ & 0,0282 & 0,3766 \\
$\vdots$ & $\vdots$ & $\vdots$ & $\ldots$ & $\vdots$ & $\vdots$ \\
$\mathrm{W}(220,220)$ & 0 & 0,0277 & $\ldots$ & 0,0282 & 0 \\
\hline
\end{tabular}

6) Mengevaluasi arah preferensi dari pasangan alernatif setiap kriteria atau nilai outranking flow.

Nilai outranking diperoleh melalui nilai outranking negatif, outranking positif, dan Net Flow pada persamaan (8), (9), dan (10). Untuk W1 diperoleh nilai berikut :

$$
\begin{aligned}
\phi^{-}(K 1) & =\frac{1}{219} * 29,8247=0,1361 \\
\phi^{+}(K 1) & =\frac{1}{219} * 53,8261=0,2457 \\
& \phi(K 1)=0.2457-0,1361=0,1096
\end{aligned}
$$

Pengurutan prioritas kesejahteraan keluarga dengan memanfaatkan nilai net flow. Nilai net flow tertinggi adalah keluarga tidak sejahtera yang paling direkomendasikan untuk diprioritaskan. Hasil evaluasi tingkat kesejahteraan masyarakat menggunakan metode Promethee ditunjukkan pada Tabel 7. 
Tabel 7. Urutan tingkat kesejahteraan masyarakat

\begin{tabular}{ccc}
\hline Alternatif & Net Flow & Urutan \\
\hline W121 & 0,7680 & 1 \\
W128 & 0,7263 & 2 \\
W125 & 0,7194 & 3 \\
$\vdots$ & $\vdots$ & $\vdots$ \\
W6 & $-0,3979$ & 220
\end{tabular}

Perangkat lunak Decision Support System (DSS) ini terdiri atas dua level pengguna yaitu Admin serta Petugas. Pada level Admin, diberikan hak akses terhadap keseluruhan fungsi pengelolaan sistem. Pada level Petugas diberi hak akses melihat data indikator dan parameter keputusan, mengelola data keluarga serta melakukan proses seleksi dan melihat hasil urutan tingkat kesejahteraan masyarakat. Gambar 2 ada tampilan beranda awal sistem setelah tahap login berhasil dilakukan baik dari sisi Admin maupun Petugas.

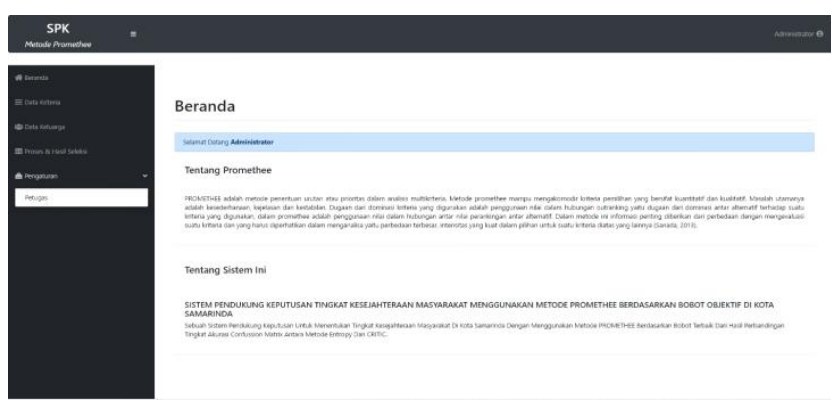

Gambar 2. Antarmuka beranda

Gambar 3 merupakan halaman data alternatif yaitu data keluarga yang akan dilakukan proses evaluasi. Pada halaman ini, operator dapat menambah

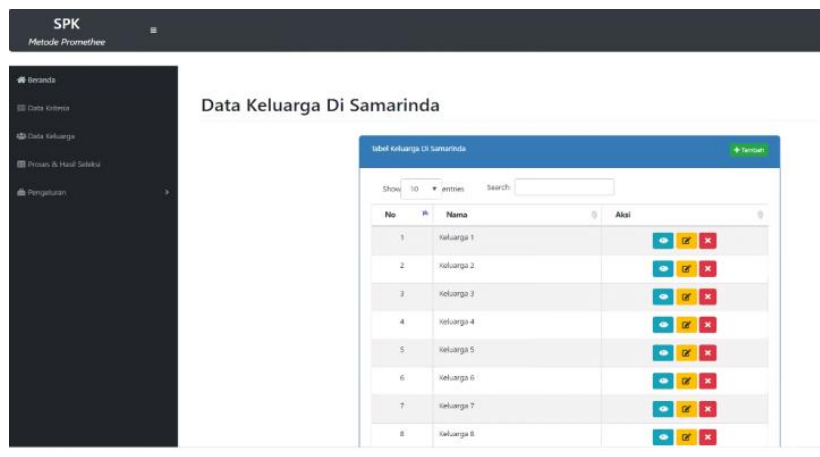

Gambar 3. Halaman data alternatif

Setiap alternatif memiliki data kondisi sosial ekonomi sesuai dengan kriteria yang digunakan. Gambar 4 merupakan form yang berisi data kondisi sosial ekonomi secara detail setiap alternatif yang digunakan dalam proses evaluasi tingkat kesejahteraan masyarakat.
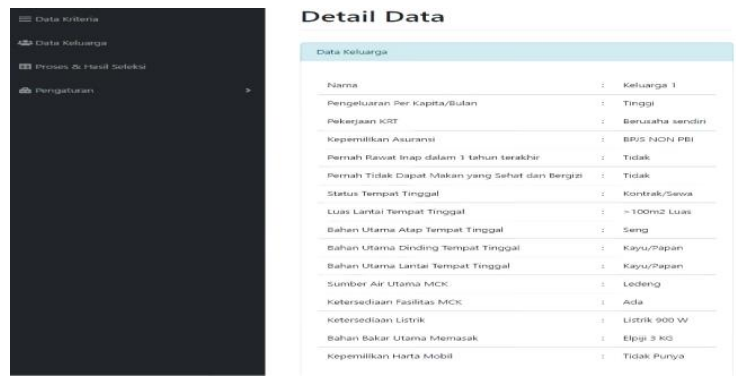

Gambar 4. Tampilan kondisi sosial ekonomi alternatif 
Kriteria yang digunakan dalam proses evaluasi tingkat kesejahteraan masyarakat dikelola di antarmuka halaman kriteria yang ditampilkan pada Gambar 5.

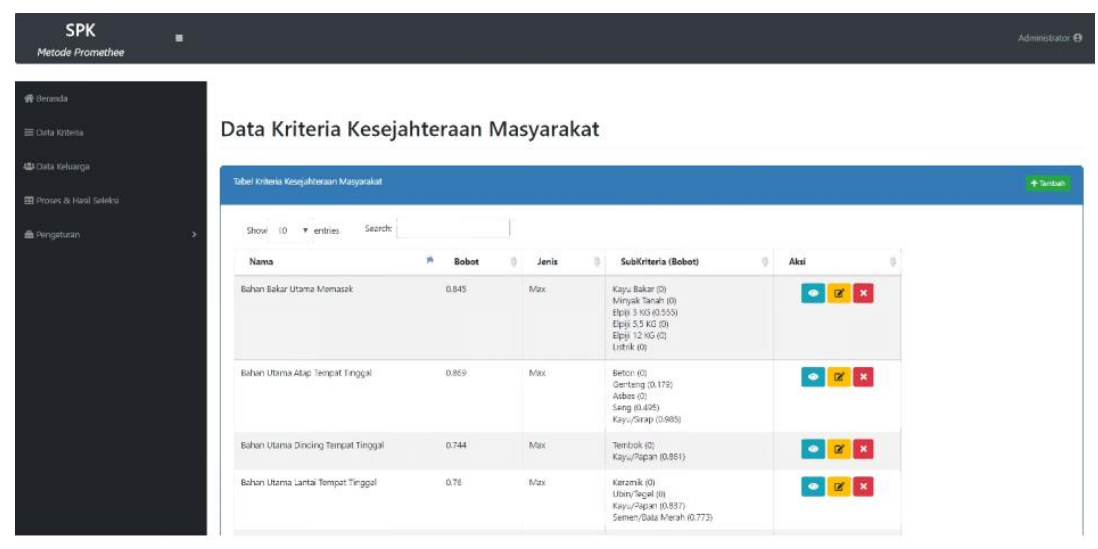

Gambar 5. Halaman Kriteria

Hasil proses evaluasi tingkat kesejahteraan masyarakat menggunakan metode Promethee ditampilkan pada antarmuka Hasil Seleksi pada Gambar 6.

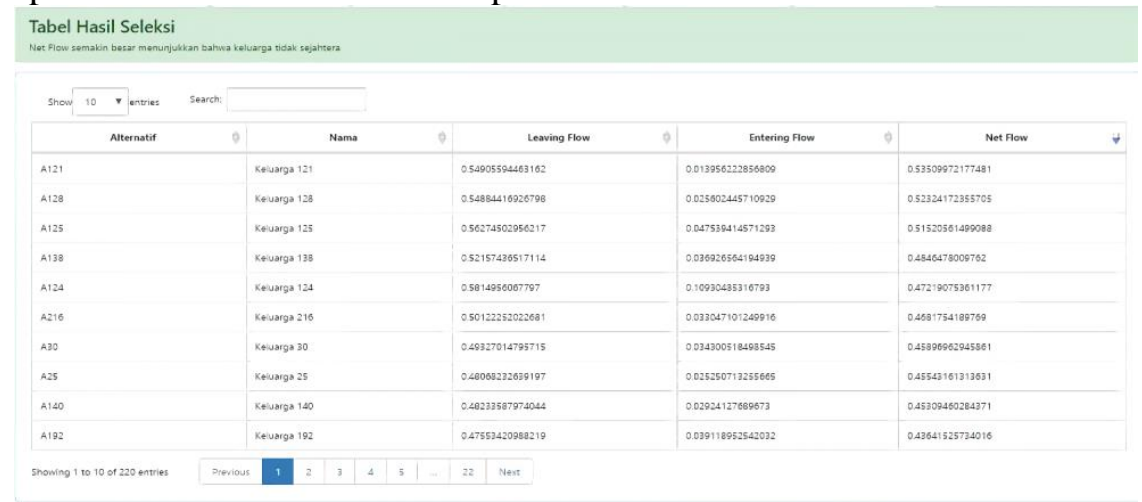

Gambar 6. Antarmuka Hasil evaluasi alternatif

Gambar 6 merupakan tampilan dari hasil evaluasi tingkat kesejahteraan masyarakat. Halaman ini menampilkan preferensi alternatif berdasarkan outranking net flow. Alternatif diurutkan secara descending, makin tinggi nilai net flow maka alternatif Keluarga terletak di urutan atas. Urutan Keluarga ini merepresentasikan bahwa makin besar net flow alternatif maka Keluarga tersebut lebih diprioritaskan karena kondisi sosial ekonomi Keluarga tersebut lebih tidak sejahtera dibandingkan Keluarga yang berada di urutan selanjutnya.

Pada hasil akhir proses seleksi diketahui bahwa urutan tingkat kesejahteraan masyarakat keluarga tidak sejahtera yang menempati urutan pertama adalah keluarga 121 , urutan kedua keluarga 128, urutan ketiga keluarga 125, dan di urutan terakhir yang merupakan keluarga paling sejahtera yaitu keluarga 6. Data yang dievaluasi sebanyak 220 keluarga, terdiri dari 21 keluarga tidak sejahtera dan 199 keluarga sejahtera. Idealnya, 21 keluarga tidak sejahtera tersebut di urutan 1-21. Dari hasil evaluasi menggunakan metode PROMETEHEE, terdapat tiga keluarga tidak sejahtera di urutan setelah urutan 21 dan tiga keluarga sejahtera berada pada urutan 1-21. Artinya, ada enam data yang berada pada urutan yang tidak tepat. Evaluasi ini menunjukkan hasil yang sama baiknya dengan hasil evaluasi pada [3] menggunakan metode EXPROM II dengan data yang sama, dimana urutan prioritas kesejahteraan masyarakat yang dihasilkan tidak jauh berbeda.

\section{Kesimpulan}

Berdasarkan hasil pelaksanaan kerangka penelitian maka simpulan yang diperoleh yaitu metode PROMETHEE cocok diterapkan pada sistem pendukung keputusan evaluasi tingkat kesejahteraan masyarakat untuk mengurutkan prioritas keluarga tidak sejahtera hingga keluarga 
sejahtera. Perangkat lunak ini dapat menjadi alat bantu serta bahan pertimbangan pengambilan keputusan saat mengevaluasi tingkat kesejahteraan masyarakat, serta dapat membantu kinerja pemerintah dalam menyalurkan bantuan agar tepat sasaran.

Selanjutnya, perlu dilakukan penelitian lebih lanjut dalam penentuan bobot setiap kriteria yang dilibatkan pada evaluasi alternatif melalui kombinasi suatu metode pembobotan dengan metode PROMETHEE. Selain itu, perlu juga penelitian lebih lanjut terkait penetapan tipe fungsi preferensi setiap kriteria serta agar menghasilkan urutan prioritas jauh lebih sesuai.

\section{Daftar Pustaka}

[1] M. Wati and B. Cahyono, "Aplikasi Multi-Criteria Decision Making Penentuan Penerima Bantuan Sosial Santunan Warga Tidak Mampu Menggunakan PROMETHEE," Jurnal Rekayasa Teknologi Informasi (JURTI), vol. 2, no. 2, pp. 208-217, 2018.

[2] M. Wati, "Analisis Metode Weighted Product dan Promethee Dalam Pemilihan Penerima Santunan Warga Tidak Mampu," Jurnal Rekayasa Teknologi Informasi (JURTI), vol. 3, no. 1, pp. 96-105, 2019.

[3] M. Wati, F. M. Lubis, and A. Tejawati, "Penentuan Prioritas Kesejahteraan Keluarga Menggunakan Metode the Extended Promethee II," ILKOM Jurnal Ilmiah, vol. 12, no. 1, pp. 71-80, 2020, doi: 10.33096/ilkom.v12i1.528.71-80.

[4] B. P. S. Samarinda, Kota Samarinda Dalam Angka 2018. Samarinda: BPS Kota Samarinda, 2018.

[5] M. Wati, B. Cahyono, and M. B. Firdaus, "Evaluation of Poverty Society for Social Assistance Recipients using PROMETHEE Method Based on Entropy Weight," Proceedings - 2nd East Indonesia Conference on Computer and Information Technology: Internet of Things for Industry, EIConCIT 2018, pp. 197-202, 2018, doi: 10.1109/EIConCIT.2018.8878646.

[6] A. Rusnawati, M. Wati, and H. J. Setyadi, "Sistem Pendukung Keputusan Penentuan Penerima Bantuan Sosial Daerah Kutai Kartanegara Menggunakan Metode TOPSIS," JURTI, vol. 1, no. 2, pp. 160-169, 2017.

[7] TNP2K, "Perkembangan Tingkat Kemisinan di Indonesia," Indonesia, 2018.

[8] M. Muslihudin, "Sistem Pendukung Keputusan Menentukan Kelayakan Penerimaan Bantuan Pengusaha Ayam Petelur oleh Dinas Peternakan Kabupaten Pesawaran Menggunakan Metode Simple Additive Weighting," vol. 14, no. 2, pp. 120-125, 2017.

[9] V. Amalia, "Komparasi Metode WP SAW Dan WASPAS Dalam Penentuan Penerima Beasiswa PMDK," Jurnal Bina Komputer, vol. 1, no. 2, pp. 122-132, 2019.

[10] E. Budiman, N. Dengen, Haviluddin, and W. Indrawan, "Integrated multi criteria decision making for a destitute problem," Proceeding - 2017 3rd International Conference on Science in Information Technology: Theory and Application of IT for Education, Industry and Society in Big Data Era, ICSITech 2017, vol. 2018-Janua, pp. 342-347, 2018, doi: 10.1109/ICSITech.2017.8257136.

[11] R. O. Siregar, D. Irmayani, and M. Masrizal, "Penerapan Metode Promethee Dalam Sistem Pendukung Keputusan Penetapan Penerima Kartu Indonesia Sehat (KIS)," JURNAL MEDIA INFORMATIKA BUDIDARMA, vol. 5, no. 2, p. 739, Apr. 2021, doi: 10.30865/mib.v5i2.2948.

[12] Mohani, C. Suhery, and U. Ristian, "Implementasi Metode Promethee Dalam Menentukan Calon Penerima Bantuan PKH Berbasis Web (Studi Kasus: Desa Tengguli Kecamatan Sajad)," Coding Jurnal Komputer dan Aplikasi, vol. 08, no. 02, pp. 43-54, 2020.

[13] BPS, Profile of Poverty in Indonesia September 2016 (eds). Statistics BPS's official news, Bureau of Central Statistics Indonesia BPS, 5:1, January, 3, 2017. 
[14] E. D. Lestari, “Analisis Peran Program Zakat Community Development (ZCD) BAZNAS dalam Mengurangi Kemiskinan di Samarinda," vol. 5, no. 1, pp. 59-73, 2019, doi: 10.21093/at.v4i2.1303.

[15] RI, Program Penanggulangan Kemiskinan Kabinet Indonesia Bersatu II. Kementerian Komunikasi Dan Informatika, 2012.

[16] I. Hermawati and E. Winarno, "Persepsi Keluarga Penerima Manfaat Tentang Program Pengentasan Kemiskinan di Indonesia," Sosio Konsepsia: Jurnal Penelitian dan Pengembangan Kesejahteraan Sosial, vol. 9, no. 3, pp. 257-270, Sep. 2020, Accessed: Nov. 29, 2021. [Online]. Available: https://ejournal.kemensos.go.id/index.php/SosioKonsepsia/article/view/1982

[17] INFID, "Menuju Indonesia Yang Lebih Setara: Laporan Ketimpangan Indonesia," International NGO Forum on Indonesian Development, OXFAM Briefing Paper, FEBRUARY 2017, 2017.

[18] B. P. S. BPS, Indikator Kesejahteraan Rakyat 2018. 2018.

[19] B. P. Statistik, "Persentase Penduduk Miskin Kalimantan Timur menurut Kabupaten/Kota (persen), 2015-2017," Badan Pusat 2018. https://kaltim.bps.go.id/dynamictable/2018/01/22/157/persentase-penduduk-miskinkalimantan-timur-menurut-kabupaten-kota-persen-2015-2017.html

[20] B. P. Statistik, "Buku Pedoman Pengawas: Survei Sosial Ekonomi Nasional 2017," Indonesia, Mar. 2017.

[21] Sanusi and J. Husna, "Sistem Pengambilan Keputusan Menggunakan Topsis Fuzzy MCDM Untuk Pemilihan Tempat Wisata Berbasis Web," vol. 4, no. 1, pp. 26-35, 2018.

[22] M. Keshavarz Ghorabaee, M. Amiri, E. Kazimieras Zavadskas, and J. Antuchevičienė, "Assessment of third-party logistics providers using a CRITIC-WASPAS approach with interval type-2 fuzzy sets," Transport, vol. 32, no. 1, pp. 66-78, 2017, doi: 10.3846/16484142.2017.1282381.

[23] H. C. Lee and C. Ter Chang, "Comparative analysis of MCDM methods for ranking renewable energy sources in Taiwan," Renewable and Sustainable Energy Reviews, vol. 92, no. April 2017, pp. 883-896, 2018, doi: 10.1016/j.rser.2018.05.007.

[24] J. P. Brans and Y. De Smet, "PROMETHEE methods," International Series in Operations Research and Management Science, vol. 233, pp. 187-219, 2016, doi: 10.1007/978-14939-3094-4_6.

[25] J. Karim, "Sistem Pendukung Keputusan Penentuan Prioritas Pembangunan Menggunakan Metode Promethee Pada Desa Ayula Kecamatan Randangan Kabupaten Pohuwato Provinsi Gorontalo," ILKOM Jurnal Ilmiah, vol. 10, no. 1, pp. 86-91, 2018, doi: 10.33096/ilkom.v10i1.232.86-91.

[26] T. Imandasari, A. Wanto, and A. P. Windarto, "Analisis Pengambilan Keputusan dalam Menentukan Mahasiswa PKL Menggunakan Metode Promethee," Jurnal Riset Komputer (JURIKOM), vol. 5, no. 3, pp. 234-239, 2018.

[27] L. Hamulian and A. Agustin, "Sistem Seleksi Penerimaan Siswa Baru Berdasarkan Cabang Olahraga Dengan Menggunakan Metode Promethee," Rabit: Jurnal Teknologi dan Sistem Informasi Univrab, vol. 5, no. 2, pp. 67-75, 2020, doi: 10.36341/rabit.v5i2.1308. 